\title{
Desenvolvimento Profissional, Tecnologia Digital e Conceitos Estatísticos na Formação de Professores que Ensinam Matemática
}

\author{
Carmélia Regina Silva Xavier, Dennys Leite Maia
}

Instituto Metrópole Digital - Universidade Federal do Rio Grande do Norte (UFRN) Av. Sen. Salgado Filho, 3000 - Lagoa Nova, CEP: 59.078-970 - Natal - RN - Brasil

carmeliaxavierxavier@gmail.com, dennys@imd.ufrn.br

\begin{abstract}
This article presents a review of the literature in search of academic papers about the use of digital technology in the training of teachers who teach mathematics, in the perspective of professional development and through work with statistical thinking. The search took place in the Google Academic and Periodical Platforms of the Coordination of Improvement of Higher Education Personnel (CAPES) on the area of Mathematics Education, from 2014 to 2019. The results showed that the use of this technology is a constant in teacher training of middle and higher levels, but it is still scarce in the formations for teachers of Early Childhood and Elementary Education.
\end{abstract}

Resumo. Este artigo apresenta uma revisão de literatura sobre trabalhos acadêmicos acerca do uso de tecnologia digital na formação de professores que ensinam Matemática sobre pensamento estatístico, na perspectiva do desenvolvimento profissional. A busca aconteceu nas Plataformas Google Acadêmico e Periódicos da Coordenação de Aperfeiçoamento de Pessoal de Nivel Superior (CAPES) sobre a área de Educação Matemática, no período de 2014 a 2019. Os resultados demonstraram que o uso dessa tecnologia é comum nas formações de professores que atuam nos níveis de Ensino Médio e Educação Superior, mas ainda é tímida nas formações para docentes da Educação Infantil e Ensino Fundamental.

\section{Introdução}

A discussão sobre formação de professores ganhou destaque com a promulgação da Lei de Diretrizes e Bases da Educação Nacional (LDBEN - Lei N 9394/96) [Brasil 1996] e, mais recentemente, do Plano Nacional de Educação (PNE) (Lei $N^{\circ}$ 13.005/2014). Enquanto o inciso II do parágrafo único do artigo 61 da LDBEN enfatiza a associação entre teorias e práticas, mediante estágios supervisionados e capacitação em serviço, a meta 12 do PNE em sua quarta estratégia fomenta a oferta de Educação Superior pública e gratuita, prioritariamente, para a formação de professores e professoras para a Educação Básica, sobretudo nas áreas de Ciências e Matemática.

Historicamente a Matemática é vista com temor por estudantes, assim como por professores que ensinam Matemática nos anos iniciais do Ensino Fundamental. Tais docentes, formados prioritariamente em Pedagogia, muitas vezes escolhem este curso de Licenciatura para fugir da Matemática, sem perceberem que serão professores desta disciplina, exatamente, numa das fases mais importantes da aprendizagem discente. A 
fuga se justifica pelas lacunas que os mesmos possuem em seu processo formativo até chegarem às universidades [Barreto 2007; Nacarato, Passos \& Mengali 2010; Maia 2012]. As dificuldades apresentadas dizem respeito não só aos conteúdos matemáticos, mas também quanto à metodologia, ou seja, à didática utilizada por esses docentes durante suas aulas [Barreto 2007; Silva et al. 2018].

Dentre as dificuldades apresentadas pelos professores estão aquelas que envolvem os conceitos estatísticos [Cazorla et al. 2010], apesar de a leitura e interpretação de dados estarem fortemente relacionadas com temas sociais emergentes. Ensinar o aluno a saber entender informações apresentadas em tabelas, gráficos e em forma de percentuais, ou até mesmo, ensiná-lo a realizar uma pesquisa desde a coleta até a análise dos dados é fundamental para o desenvolvimento de um cidadão com olhar crítico e reflexivo.

A relevância e importância de se trabalhar os conceitos estatísticos já era tratada no bloco de conteúdo Tratamento da Informação, segundo a organização para o ensino de Matemática nos Parâmetros Curriculares Nacionais (PCN) [Brasil 1997] e agora, vinte anos depois, é reforçada pela unidade temática Probabilidade e Estatística, da Base Nacional Comum Curricular (BNCC) [Brasil 2017]. Esta última, inclusive, alinhando-se ao crescimento e influência das tecnologias digitais na sociedade, enfatiza a necessidade de explorar tais ferramentas no ensino e aprendizagem da Matemática e, especificamente, dos conceitos estatísticos. Segundo a BNCC, esta unidade temática [Brasil 2017, p.272]:

(...) propõe a abordagem de conceitos, fatos e procedimentos presentes em muitas situações-problema da vida cotidiana, das ciências e da tecnologia. Assim, todos os cidadãos precisam desenvolver habilidades para coletar, organizar, representar, interpretar e analisar dados em uma variedade de contextos, de maneira a fazer julgamentos bem fundamentados e tomar as decisões adequadas. Isso inclui raciocinar e utilizar conceitos, representações e índices estatísticos para descrever, explicar e predizer fenômenos [Brasil 2017, p.272].

Por razões diversas, a formação docente inicial dificilmente contemplará na totalidade as demandas formativas dos professores e os avanços e demandas da sociedade, principalmente por estar demarcada em tempo histórico. Por isso a formação continuada de professores, na perspectiva do desenvolvimento profissional [Ponte 1998], tem relevância e é estratégica por proporcionar reflexão docente ao longo de, e alinhada, à sua prática profissional.

Nesse contexto, as tecnologias digitais podem surgir tanto como elemento da formação, quanto meio para a sua realização ou ampliação. $O$ uso de recursos tecnológicos permite que os professores, enquanto aprendizes, ampliem o repertório de recursos didáticos a serem utilizados em suas aulas, fazendo uso de ferramentas e linguagens inerentes ao atual contexto [Almeida; Valente 2011]. Assim, a tecnologia digital aparece como uma possibilidade com grande potencial, mas que precisa ser observada como vem sendo usada pelos docentes nas formações continuadas e em serviços dos professores que ensinam Matemática.

Diante dessa realidade, este trabalho é um recorte de uma pesquisa de mestrado, em desenvolvimento, relacionada à formação de professores que ensinam Matemática nos anos iniciais do Ensino Fundamental acerca de conceitos estatísticos numa perspectiva do desenvolvimento profissional com suporte de tecnologias digitais. A partir 
de uma revisão bibliográfica, queremos responder a seguinte questão: Como a tecnologia digital e os conceitos estatísticos são explorados nas formações continuadas de professores que ensinam Matemática nos anos iniciais do Ensino Fundamental?

Para isso, buscamos trabalhos acadêmicos registrados nas Plataformas Google Acadêmico e Periódicos da Coordenação de Aperfeiçoamento de Pessoal de Nível Superior (CAPES) sobre a área de Educação Matemática, no período entre os anos 2014 e 2019. Além desta introdução, o presente artigo trará uma fundamentação teórica sobre os itens de interesse, a metodologia utilizada para realização da revisão bibliográfica, os resultados encontrados, as considerações finais e as referências consultadas.

\section{Fundamentação Teórica}

O professor que ensina Matemática nos anos inicias do Ensino Fundamental tem responsabilidade no desenvolvimento do raciocínio lógico das crianças com idade entre seis e dez anos. Além da importância imediata para a vida do educando, os PCN preconizam que um bom ensino de Matemática, nesse período, forma uma base para os anos posteriores e dá apoio à construção de outras áreas, pois "(...) interfere fortemente na formação de capacidades intelectuais, na estruturação do pensamento e na agilização do raciocínio dedutivo do aluno" [Brasil 1998, p. 15].

Afirmações como essas nos fazem refletir sobre como devemos pensar as formações de professores. Os baixos resultados apresentados pelas avaliações externas como a Prova Brasil, por exemplo, vem se repetindo por muitos anos, provavelmente, pelo fato de que, na vida, costumamos reproduzir aquilo que vivenciamos e portanto, não parece ser diferente na escola. Se o docente não teve uma boa formação escolar, no que diz respeito ao ensino de Matemática, provavelmente, isto se repetirá na sua sala de aula. Transformar essa realidade requer repensar quais fatores corroboram para $o$ desencadeamento desse insucesso. Dentre esses fatores está o modelo de formação docente continuada e em serviço que é oferecido aos professores que ensinam Matemática, no que diz respeito à sua condução e à integração de tecnologias digitais como sugestão metodológica para ampliar as possibilidades pedagógicas.

Em relação ao tipo de formação continuada e em serviço, é necessário pensar num formato em que o foco não seja a exposição de conteúdos traçados pelo formador e apresentados ao professor, durante os encontros formativos. Apesar das autoras Nacarato, Mengali e Passos (2009) afirmarem que as lacunas também são de cunho conteudista, essa formação precisa ser planejada a partir da necessidade do professor e da realidade em que atua, pensando nos desafios do seu contexto e no seu desenvolvimento profissional.

De acordo com Ponte (1998), o termo desenvolvimento profissional emergiu na literatura educacional como forma de demarcar uma diferenciação entre seu princípio de formação e aquele chamado tradicional. Iniciativas tradicionais não se demonstram contínuas na formação docente, porque geralmente são associadas a cursos, capacitações e treinamentos, os quais caracterizam um movimento de "fora para dentro", já que as necessidades formativas são estabelecidas pelo formador e, por vezes, não correspondem àquelas presentes na sala de aula e na prática dos professores.

Ao optar por trabalhar a formação continuada e em serviço, na perspectiva do desenvolvimento profissional, ações como apresentar e utilizar tecnologias digitais 
durante os encontros formativos permitirão que os professores, enquanto aprendizes, trabalhem colaborativamente e ampliem o repertório de recursos didáticos que poderão fazer uso em suas aulas [Maia; Castro-Filho 2016]. Neste sentido, a tecnologia digital apresenta grande potencial, mas seu uso precisa ser observado.

Nesse sentido, Ponte (1997) ainda ressalta a possibilidade que as tecnologias digitais se apresentam como ferramenta de trabalho e como fonte de ideias e de inspiração no sentido de minimizar as lacunas formativas acerca do ensino e aprendizagem matemáticos. Porém, para que isso aconteça, se faz necessário pensar se esses recursos estão chegando em sala de aula e como acontece seu uso pedagógico. De acordo com Maia e Barreto (2014), estudantes de Pedagogia, por exemplo, possuem reduzido espaço formativo para o ensino da Matemática com uso de tecnologias digitais e essa especificidade, caracteriza os professores dos anos iniciais do Ensino Fundamental, público-alvo deste trabalho.

Para os referidos autores, tal déficit acarreta numa visão limitada de estratégias do uso desses recursos, cada vez mais presentes na escola, na disciplina com maiores índices de dificuldade durante a Educação Básica. A formação continuada tem uma importante função, pois para essa tecnologia trazer alterações positivas no processo educativo, elas precisam ser compreendidas e incorporadas pedagogicamente para poder garantir que o seu uso, realmente, faça a diferença [Kenski 2007].

$\mathrm{Na} \mathrm{BNCC}$, a tecnologia digital está presente em todos os componentes curriculares, inclusive na Matemática e em muitas das habilidades, nas diversas unidades temáticas. Considerada como um potencial recurso educacional compõe a quinta competência geral do documento afirmando a importância de:

Compreender, utilizar e criar tecnologias digitais de informação e comunicação de forma crítica, significativa, reflexiva e ética nas diversas práticas sociais (incluindo as escolares) para se comunicar, acessar e disseminar informações, produzir conhecimentos, resolver problemas e exercer protagonismo e autoria na vida pessoal e coletiva [Brasil 2017, p.9].

Além de compor uma competência geral da BNCC, a tecnologia digital também aparece como uma das competências específicas da Matemática defendendo a necessidade de "(...) utilizar processos e ferramentas matemáticas, inclusive tecnologias digitais disponíveis, para modelar e resolver problemas cotidianos, sociais e de outras áreas de conhecimento, validando estratégias e resultados" [Brasil 2017, p.265].

Apesar da importância do tema, já existem pesquisas que apontam uma menor produção de recursos educativos digitais referentes às unidades temáticas Probabilidade e Estatística e Grandezas e Medidas, em detrimento de outras unidades que utilizam algoritmos básicos para a resolução de exercícios e o raciocínio lógico-matemático [Melo, Costa \& Maia 2017]. O menor número de produção dos recursos educativos digitais não diminui a importância de se trabalhar com o tema, pelo contrário, demonstra a necessidade de investir nessa temática, inclusive na formação de professores. Ademais, todas essas habilidades indicadas para os alunos, devem contemplar também o professor, como aprendiz, durante sua formação. Considerando que a formação inicial não é capaz de abarcar em sua totalidade, a formação continuada e em serviço deve trabalhar tais habilidades na perspectiva do desenvolvimento profissional. 


\section{Percurso Metodológico da Revisão Bibliográfica}

A pesquisa bibliográfica se constitui num procedimento metodológico utilizado na busca de soluções para um problema de pesquisa. Lima e Mioto (2007) salientam que nessa abordagem é necessária a escolha do método de pesquisa empregado, expor a maneira como ocorreu a construção do desenho metodológico e a escolha pelos procedimentos utilizados. O levantamento inicial permite ao pesquisador a elaboração de ensaios que favorecem a contextualização, problematização e uma primeira validação do quadro teórico a ser utilizado na investigação. $\mathrm{O}$ aprofundamento dessa análise pode se constituir em estudo do tipo Estado da Arte que Gil (2002) denomina como sendo a identificação das fontes ligadas ao objeto de estudo. O autor identifica esta etapa do trabalho como uma procura de fontes capazes de fornecer as respostas adequadas à solução do problema proposto que tem como objetivo realizar levantamentos do que se conhece sobre um determinado assunto a partir das pesquisas realizadas em uma determinada área e tempo.

Baseado nesses conceitos, este artigo tem caráter teórico e foi guiado por uma combinação de elementos de duas abordagens metodológicas - pesquisa bibliográfica e estado da arte - com vistas a compreender o contexto do objeto de estudo e identificar experiências semelhantes realizadas. A busca teve como foco identificar como as tecnologias digitais e conceitos estatísticos são abordados nas formações de professores que ensinam Matemática nos anos iniciais do Ensino Fundamental na perspectiva de desenvolvimento profissional.

O procedimento de busca de trabalhos acadêmicos foi realizado nas Plataforma Google Acadêmico1 e Periódicos da Coordenação de Aperfeiçoamento de Pessoal de Nível Superior (CAPES), no período entre os anos 2014 e 2019. Em ambas plataformas, foram utilizadas as seguintes palavras de busca: "tecnologia digital"; "conceitos estatísticos"; "professores que ensinam Matemática"; "desenvolvimento profissional" e "formação docente". A busca foi realizada no modo avançado e foram consideradas, apenas, resultados em Língua Portuguesa como uma forma de conhecer, especificamente, o Estado da Arte em nosso País sobre a temática em discussão. Assim, trabalhos em Português, mas realizados em contextos fora do Brasil foram descartados. Em estudo futuro, a busca será ampliada, inclusive, para outras línguas estrangeiras.

Como este estudo é um recorte de uma dissertação de mestrado, optamos pela busca que considerava, pelo menos, um dos aspectos para analisar, futuramente, diferentes contribuições metodológicas a respeito de cada uma categorias de análise. Assim, a partir das palavras de busca foram encontrados 74 (setenta e quatro) trabalhos em Educação Matemática que relacionavam, pelo menos, uma das nossas categorias de análise, quais sejam: desenvolvimento profissional, conceitos estatísticos e utilização de tecnologias digitais. Um primeiro recorte foi feito a partir da leitura do título e dos resumos com o intuito de analisar a relevância dos trabalhos para nosso interesse de pesquisa. Ao final deste procedimento, restaram apenas 17 (dezessete) trabalhos que foram categorizados e protocolados também por etapas de ensino, quais sejam: Educação Infantil (EI); Ensino Fundamental I e II (EF I e EF II, respectivamente); Ensino Médio (EM) e Ensino Superior (ES). 
Após essa classificação, identificamos que a maior parte dos trabalhos se concentra no mesmo público deste estudo. Isso porque 8 (oito) trabalhos, que representam $47,05 \%$, tratavam sobre professores que atuam na Educação Infantil e anos iniciais do Ensino Fundamental, portanto, professores formados, prioritariamente, nos cursos de Licenciatura em Pedagogia. Os demais trabalhos, 3 (quatro) - 17,65\% - focaram os anos finais do Ensino Fundamental2 e o Ensino Médio, portanto, Licenciados em Matemática, e seis $(35,30 \%)$ falavam do contexto da Educação Superior, sem precisar ou especificar qual curso de graduação ou licenciatura estavam analisando.

Ao final, dos 17 (dezessete) trabalhos, apenas 3 (três) abordavam as três categorias relacionadas a este estudo, quais sejam: Desenvolvimento Profissional (DP), Conceitos Estatísticos (EST) e Adoção de Tecnologias Digitais (TD). Deste montante, apenas um abordou, de forma específica, professores que ensinam Matemática nos anos iniciais, ou seja, egressos dos cursos de Licenciatura em Pedagogia. O quadro 01 apresenta a sistematização desses três trabalhos selecionados.

Quadro 1. Trabalhos acadêmicos selecionados.

\begin{tabular}{|c|c|c|l|l|l|l|l|l|}
\hline $\mathrm{N}^{\circ}$ & \multicolumn{1}{|c|}{ Autor } & Ano & \multicolumn{1}{|c|}{ Título } & Plataforma & Nível & DP & EST & TD \\
\hline 1 & Araújo, M. & 2017 & $\begin{array}{l}\text { Práticas investigativas e } \\
\text { webquest: construindo } \\
\text { interfaces para o ensino sobre } \\
\text { Tratamento da Informação } \\
\text { para além do paradigma do } \\
\text { exercício }\end{array}$ & $\begin{array}{c}\text { Google } \\
\text { Acadêmico }\end{array}$ & EF I & Sim & Sim & Sim \\
\hline 2 & Berlikowski, M. & 2018 & $\begin{array}{l}\text { As abordagens metodológicas } \\
\text { e o perfil dos professores que } \\
\text { lecionam Estatística no Ensino } \\
\text { Superior }\end{array}$ & $\begin{array}{c}\text { Google } \\
\text { Acadêmico }\end{array}$ & ES & Sim & Sim & Sim \\
\hline 3 & Silva, N. & 2018 & $\begin{array}{l}\text { Níveis de Letramento } \\
\text { Estatístico em um curso de } \\
\text { formação continuada }\end{array}$ & $\begin{array}{c}\text { Google } \\
\text { Acadêmico }\end{array}$ & ES & Sim & Sim & Sim \\
\hline
\end{tabular}

Fonte: elaborado pelos autores.

$\mathrm{Na}$ seção seguinte, cada um desses trabalhos serão analisados e apresentados como as três categorias de análise foram exploradas.

\section{Resultados e discussões}

Discorrendo sobre os trabalhos os quais as três categorias de análise foram contempladas, Araújo (2017), na condição de professora, formadora e pesquisadora, tinha como objetivo investigar o ensino sobre Tratamento da Informação, utilizando WebQuest, uma metodologia de ensino que privilegia uma pesquisa orientada utilizando a internet como principal fonte de informação, com o intuito de propor práticas investigativas com o uso de tecnologias digitais. Nessa pesquisa o recurso digital foi apresentado como uma possibilidade de promover a (auto)formação, o letramento estatístico e o ensino qualitativamente positivo sobre tratamento da informação para os primeiros anos

2 Um trabalho contemplava professores tanto dos anos iniciais, quanto dos anos finais do Ensino Fundamental. 
escolares.

Essa pesquisa sobre formação de professores ocorreu no município de Marabá /PA, onde a WebQuest foi utilizada para motivar os sujeitos envolvidos e apresentar o tema relativo a cada encontro formativo. Além disso, por meio dessa metodologia foi possível disponibilizar atividades que fossem desafiadoras e tratassem sobre $\mathrm{o}$ pensamento estatístico, fornecer os indicadores qualitativos e/ou quantitativos do desempenho dos professores e por fim, concluir com um desfecho de forma clara, breve e simples, relembrando os objetivos da atividade e deixando pistas para pesquisas ou atividades futuras sobre a mesma temática. A ideia inicial era que os professores participantes dessa pesquisa vivenciasse a mesma experiência com seus alunos, construindo uma WebQuest para suas turmas e levando os relatos para serem socializados durante a pesquisa, mas devido o tempo, não foi possível.

Mesmo assim, os professores avaliaram que a experiência formativa possibilitou novas reflexões acerca do vivido, destacando a relevância das práticas investigativas na promoção de atitudes de interação e valorização dos sujeitos da aprendizagem no ambiente educativo, e portanto, contribuindo para o desenvolvimento profissional dos envolvidos. Um dos fatores que mais contribuíram para esse desenvolvimento profissional foi o acesso a tecnologia digital, uma vez que os professores revelaram não conhecer tal ferramenta e não ter muito domínio tecnológico, apesar de trabalharem com alunos denominados nativos digitais [Prensky 2001].

O trabalho de Araújo (2017) foi o que mais se assemelhou às características da pesquisa a qual essa revisão bibliográfica se propõe a contribuir, pois trata-se de uma experiência vivenciada com docentes dos anos iniciais do Ensino Fundamental, numa pesquisa realizada no ambiente de trabalho desses docente. Além disso, a autora do trabalho analisado dialoga com o pensamento dos autores apresentados nessa revisão quando, por exemplo, acredita que a ação pedagógica docente está diretamente relacionada com a formação do professor e sua experiência em toda sua história escolar, seja como aluno ou docente.

Berlikowski (2018) em sua tese teve como objetivo analisar as concepções da Educação e caracterizar os professores de Estatística que atuam na Educação Superior. Para isso, realizou sua pesquisa com 14 docentes com o intuito de verificar de que forma esses profissionais ressignificam e moldam as suas práticas pedagógicas. Os professores selecionados, pertenciam à uma instituição pública (5) e uma privada (9) do Rio Grande do Sul e responderam questões sobre formação inicial e continuada, aspectos pedagógicos e metodológicos de suas trajetórias enquanto docentes de Estatística. Ao final da pesquisa, percebeu-se que o ensino de Estatística na Educação Superior, independe da sua formação inicial dos seus docentes, pois as deficiências deixadas tanto na licenciatura quanto no bacharelado foram sanadas por meio de formação continuada e outras estratégias para facilitar o entendimento e a aprendizagem dos seus alunos, a partir do desenvolvimento profissional docente.

A tecnologia digital nesta pesquisa foi utilizada como um facilitador para aprendizagem da Estatística, sendo percebida como um recurso que alunos e professores podem utilizar tanto nos cálculos, quanto na construção manual dos gráficos, tornandose mais fácil o trabalho com um número maior de dados e num período de tempo mais curto. Para a autora da tese esse facilitador pode se apresentar por meio de computadores 
portáteis, tablets, softwares e aparelhos celulares.

Embora a pesquisa de Berlikowski (2018) tenha sido direcionada para a Educação Superior, o trabalho contribui com a revisão apresentada neste artigo quando reafirma a importância da formação continuada e em serviço e quando reconhece que a formação inicial, apenas, não é capaz de abarcar em sua totalidade todo o conhecimento necessário para a ação docente. Além disso, ressaltou a importância do uso da tecnologia digital utilizada de forma pedagógica e a relevância de se trabalhar Estatística em todos os níveis de ensino, por se tratar de um conhecimento necessário para a vida.

O terceiro e último trabalho selecionado, que apresentou todas as categorias de análise, foi o de Silva (2018) que tinha como objetivo apresentar os conteúdos e a abordagem utilizada no Ambiente Virtual de Aprendizagem (AVA) do curso de formação continuada de Letramento Estatístico de uma universidade privada, bem como os conteúdos de Estatística nos documentos oficiais de Brasil, EUA, França e Espanha, e identificar os níveis de Letramento Estatístico apresentados pelos grupos no Trabalho Final do Curso. O curso Letramento Estatístico de 120 horas foi ofertado para os funcionários-tutores da IES, com formação superior e pós-graduação, em três módulos, realizadas junto ao AVA. Cada um dos módulos contemplou conteúdos que abordaram o Letramento Estatístico, para que os participantes pudessem vivenciar, analisar e utilizar em seu cotidiano.

$\mathrm{O}$ autor conclui a pesquisa afirmando que os resultados foram positivos em relação ao Letramento Estatístico, pois $60 \%$ dos trabalhos concluídos obtiveram o Nível Científico, logo estavam letrados estatisticamente. Afirma ainda que os cursistas possuem as habilidades de ler, compreender, analisar, avaliar, fazer inferência, bem como comunicar de forma crítica e contextualizada as informações submetidas a tratamento estatístico, habilidades importantes para o exercício da cidadania. Para o autor, a tecnologia aparece no ensino da Estatística com um papel de descentralizador do conhecimento, de levar às pessoas, em suas rotinas, uma ferramenta que lhes possibilite ter uma melhor compreensão do mundo. Apesar da conclusão positiva, o autor afirma a necessidade da continuação da formação.

A pesquisa desse autor foi contemplada na revisão bibliográfica após o critério de busca pelo fato de que o tutor, apesar de não ser o professor dos alunos com os quais trabalha, é compreendido como um sujeito que ensina fazendo as vezes do docente em cursos ocorridos em AVA. Com os resultados deste trabalho, foi possível perceber o quanto a tecnologia digital pode contribuir no processo educacional, independente da formação adquirida até então e da forma como essa formação é realizada, seja presencialmente ou virtualmente. Demonstra ainda que, a necessidade de continuidade da formação em serviço é importante em toda faixa etária, nível de formação docente, ou ambiente formativo.

\section{Considerações}

Ao concluir esta revisão bibliográfica foi possível perceber a importância e necessidade das formações continuadas em serviço contemplando a Estatística, tendo em vista a obrigação da escola de promover um ensino matemático que oportunize ao aluno a busca por uma boa interpretação dos fatos sociais por meio da elaboração de problemas e temas 
envolvendo o dia a dia. Essa obrigatoriedade é posta pelos documentos oficiais, como a BNCC, e indicada pela revisão bibliográfica quando demonstrou a ausência da temática, principalmente, nas formações de professores que ensinam Matemática nos anos iniciais do Ensino Fundamental.

Algo semelhante ocorre com a tecnologia digital quando observa-se seu uso nas formações de professores dessa mesma etapa de ensino. Nos trabalhos analisados durante a revisão bibliográfica, a tecnologia digital foi muito mais presente quando a formação envolvia professores dos anos finais do Ensino Fundamental, Ensino Médio e Educação Superior. Além da frequência desse recursos nas formações, outro fator que merece futuras análises é o como essa tecnologia é utilizada, uma vez que nem sempre ela aparece como recurso pedagógico. Apesar da relevância do trabalho com conceitos estatísticos associado a tecnologia digital demonstrada pelos trabalhos apresentados no quadro 1 , ainda é tímida a frequência desses dois componentes juntos nas formações continuadas destinadas aos pedagogos, fato esse que ficou evidente não apenas nos três trabalhos que contemplaram as categorias de análise (conceitos estatísticos, tecnologia digital e desenvolvimento profissional) dessa revisão bibliográfica, mas na totalidade dos trabalhos lidos.

Diante do exposto esta revisão evidencia a necessidade de investir em formação de professores que ensinam Matemática nos anos iniciais do Ensino Fundamental de modo a inserir, de fato, o trabalho com os conceitos estatísticos e a tecnologia digital, tendo em vista a importância das duas temáticas para o desenvolvimento de habilidades específicas e, consequentemente, para o desenvolvimento profissional docente. Assim sendo, conclui-se a relevância da pesquisa a qual essa revisão se propôs a contribuir analisando trabalhos existentes dentro do escopo pesquisado.

\section{Referências}

Almeida, M. de; Valente, J. A. (2011) Tecnologias e currículo: trajetórias convergentes ou divergentes. São Paulo: Paulus, v. 1, p. 93.

Araújo, M. et al. (2017). "Práticas investigativas e webquest: construindo interfaces para o ensino sobre tratamento da informação para além do paradigma do exercício".

Barreto, M. (2007). "Desafios aos pedagogos no ensino de Matemática". In: Sales, J. et al. Formação e Práticas Docentes. Fortaleza: EdUECE, p.243-254.

Berlikowski, M. et al. (2018). "As abordagens metodológicas e o perfil dos professores que lecionam estatística no ensino superior".

Brasil (1996). Lei de Diretrizes e Bases da Educação Nacional (LDBEN) - Lei N $^{\circ}$ 9394/96. Poder Executivo: Brasília - DF.

. (1999) Ministério da Educação. Parâmetros Curriculares Nacionais para o Ensino Fundamental. Brasília.

(2014) Plano Nacional de Educação (PNE) - Lei N ${ }^{\circ}$ 13.005/2014. Poder

Executivo: Brasília - DF. 
. (2016) Ministério da Educação. Secretaria da Educação Básica. Base Nacional Comum Curricular. Brasília - DF. Disponível em: $<$ http://basenacionalcomum.mec.gov.br>. Acesso em: 10 abr. 2019.

Cazorla, I. M.; Santana, E. R. dos S.; Nagamine, C. M. L.; Vendramini, C. M. M.; Silva, C. B.; Silva, E. D.; Hernandez, H.; Oliveira, M. S.; Utsumi, M. C.; Magina, S. M. P.; Kataoka, V. Y. (2010) Do Tratamento da Informação ao Letramento Estatístico. In: Cazorla, I.; Santana, E. (Orgs.). Série Alfabetização Matemática, Estatística e Científica. Itabuna: Via Litterarum.

Gil, A. (2002). “Como Elaborar Projetos de Pesquisa”. 4ª ed. São Paulo, Atlas.

Kenski, V. (2007). "Educação e Tecnologias: o novo ritmo da informação". Campinas, SP. Papirus.

Lima, T.; MIOTO, R. (2007). "Procedimentos metodológicos na construção do conhecimento científico: a pesquisa bibliográfica". Katálysis, Florianópolis, v. 10, n. esp, p. 37-45, abr.

Maia, D.; Barreto, M. C. (2014) "Ensinar Matemática com o uso de tecnologias digitais: uma análise a partir da representação social de estudantes de Pedagogia".

Maia, D.; Castro-Filho, J. (2016). "Aprendizagem colaborativa apoiada por TDIC na Educação Matemática de professores: tecendo argumentos para efetivação de uma proposta". Anais do Congresso Regional sobre Tecnologias na Educação (Ctrl+E 2016). Natal: CEUR-WS. p. 461-471.

Melo, E.; Costa, C.; Maia, D. (2017). "Recursos educativos digitais para Educação Matemática: um levantamento para dispositivos móveis", In: II Anais do Congresso sobre Tecnologias na Educação (Ctrl+E 2017), Mamanguape/PB: CEUR-WS.

Nacarato, A.; Mengali, B.; Passos, C. (2009). “A Matemática nos anos iniciais do Ensino Fundamental: tecendo fios do ensinar e do aprender”. Belo Horizonte: Autêntica.

Ponte, J. (1997). “As novas tecnologias e a educação”. Lisboa: Editora Texto.

Ponte, J. (1998). “Da formação ao desenvolvimento profissional”. Lisboa: APM.

Prensky, M. (2001) Nativos digitais, imigrantes digitais. On the horizon, v. 9, n. 5, p. 16.

Silva, N. (2018). Níveis de letramento estatístico em um curso de formação continuada. 